\title{
Article \\ Chemical Composition, Antioxidant, and Anti-Inflammatory Activity of Essential Oil from Omija (Schisandra chinensis (Turcz.) Baill.) Produced by Supercritical Fluid Extraction Using $\mathrm{CO}_{2}$
}

\author{
Jae-Hoon Lee ${ }^{1}$, Yun-Yeol Lee ${ }^{1}$, Jangho Lee ${ }^{1}$, Young-Jin Jang ${ }^{2, *}$ and Hae-Won Jang ${ }^{3, *(D)}$ \\ 1 Korea Food Research Institute, 245 Nongsaengmyeong-ro, Iseo-myeon, Wanju-Gun, \\ Jeollabuk-do 55365, Korea; leejaehoon@kfri.re.kr (J.-H.L.); lyy@kfri.re.kr (Y.-Y.L.); jhlee@kfri.re.kr (J.L.) \\ 2 Major of Food Science \& Technology, Seoul Women's University, Seoul 01797, Korea \\ 3 Department of Food Science and Biotechnology, Sungshin Women's University, Seoul 01133, Korea \\ * Correspondence: jyj@swu.ac.kr (Y.-J.J.); hwjang@sungshin.ac.kr (H.-W.J.); Tel.: +82-2-970-5638 (Y.-J.J.); \\ +82-2-920-2695 (H.-W.J.)
}

\section{check for}

updates

Citation: Lee, J.-H.; Lee, Y.-Y.; Lee, J.; Jang, Y.-J.; Jang, H.-W. Chemical Composition, Antioxidant, and Anti-Inflammatory Activity of Essential Oil from Omija (Schisandra chinensis (Turcz.) Baill.) Produced by Supercritical Fluid Extraction Using $\mathrm{CO}_{2}$. Foods 2021, 10, 1619. https:// doi.org/10.3390/foods10071619

Academic Editor: Kieran

N. Kilcawley

Received: 7 June 2021

Accepted: 7 July 2021

Published: 13 July 2021

Publisher's Note: MDPI stays neutral with regard to jurisdictional claims in published maps and institutional affiliations.

Copyright: (c) 2021 by the authors. Licensee MDPI, Basel, Switzerland. This article is an open access article distributed under the terms and conditions of the Creative Commons Attribution (CC BY) license (https:// creativecommons.org/licenses/by/ $4.0 /)$

\begin{abstract}
Schisandra chinensis (Turcz.) Baill., which is known as omija in South Korea, is mainly cultivated in East Asia. The present study aimed to investigate the chemical composition of essential oil from the omija (OMEO) fruit obtained by supercritical fluid extraction using $\mathrm{CO}_{2}$ and to confirm the antioxidant and anti-inflammatory activity of OMEO using HaCaT human keratinocyte and RAW 264.7 murine macrophages. As a result of the chemical composition analysis of OMEO using gas chromatography-mass spectrometry, a total of 41 compounds were identified. The detailed analysis results are sesquiterpenoids (16), monoterpenoids (14), ketones (4), alcohols (3), aldehydes (2), acids (1), and aromatic hydrocarbons (1). OMEO significantly reduced the increased ROS levels in HaCaT keratinocytes induced by UV-B irradiation $(p<0.05)$. It was confirmed that 5 compounds ( $\alpha$-pinene, camphene, $\beta$-myrcene, 2-nonanone, and nerolidol) present in OMEO exhibited inhibitory activity on ROS production. Furthermore, OMEO showed excellent anti-inflammatory activity in RAW 264.7 macrophages induced by lipopolysaccharide. OMEO effectively inhibited NO production $(p<0.05)$ by suppressing the expression of the iNOS protein. Finally, OMEO was investigated for exhibition of anti-inflammatory activity by inhibiting the activation of NF-kB pathway. Taken together, OMEO could be used as a functional food ingredient with excellent antioxidant and antiinflammatory activity.
\end{abstract}

Keywords: omija (Schisandra chinensis (Turcz.) Baill.); antioxidant; anti-inflammatory; gas chromatography-mass spectrometry

\section{Introduction}

Reactive oxygen species (ROS) are known as the representative products of cellular oxygen metabolism [1]. These ROS are regulated to an appropriate level by various enzymes (e.g., catalase, glutathione peroxidase, and superoxide dismutase) present in the body [2]. Otherwise, ROS is overproduced, putting oxidative stress on various tissues, cells, and DNA in the body, eventually causing damage [3]. It is known to cause fatal diseases such as cancer, cardiovascular disease, stroke, and atherosclerosis [1,4]. Reactive nitrogen species (RNS) are another important class of chemically reactive species in the body. Among them, nitric oxide (NO) is a representative RNS, as a small biologically active molecule that plays an important role in various physiological process in the body, such as vasodilation, neurogenesis, sound healing, and modulation of innate immune responses [5]. Therefore, it is important to maintain homeostasis of nitric oxide levels. If homeostasis is broken, it can cause nitrosative damage to biological targets or organelles (e.g., proteins, lipids, DNA, and mitochondria), which can lead to cancer, stroke, or neurodegenerative 
diseases [6,7]. Nowadays, many scientific researchers are reporting studies to find natural substances with both antioxidant and anti-inflammatory activities that properly regulate ROS and RNS [8,9]. In addition, they have confirmed that there is some relationship between antioxidant and anti-inflammatory activities [8]. This includes the fact that ROS is associated with a variety of inflammatory responses $[9,10]$.

Schisandra chinensis (Turcz.) Baill. (Chinese magnolia vine), which also known as omija in South Korea, is mainly cultivated in East Asian countries, including China, Japan, East Russia, and South Korea [11]. This herbal plant belonging to the Magnoliaceae family is well known as a medicinal herb that has long been used to treat diseases such as dyspnea, hepatitis, bronchitis, and coronary heart disease $[12,13]$. This is due to the various bioactive compounds contained in omija, such as lignans, terpenoids, and polysaccharides [14-16]. In particular, according to many studies, lignans are the main bioactive component of omija, and various functional activities, such as antioxidant, anti-cancer, and anti-inflammatory activity, of schisandrin, a representative substance among lignans, have been reported $[17,18]$. Moreover, in recent studies, there have been reports confirming the antioxidant and immune-regulatory activity of S. chinensis fruit extract $[19,20]$. Hwang et al. [19] reported that $S$. chinensis fruit extract exhibits free-radical-scavenging activity, and Chen et al. [20] reported that S. chinensis fruit extract increases the phagocytic activity of macrophages. Through these studies, the possibility of using S. chinensis extract as a food additive is suggested, and it is confirmed that it can be widely used as an additive for health promotion in daily products, such as various health food and medicines. Although there are many studies on the functional ingredients of omija, studies on essential oils of omija fruits are insignificant.

Essential oils are secondary metabolites of aromatic plants that are complex mixtures of aromatic compounds, volatile compounds, and hydrophobic compounds from leaves, flowers, and seeds of plants [21]. Various functional effects, such as antioxidant, antiinflammatory, antimicrobial, antiviral, and anticancer activity, of essential oils extracted from various aromatic plants, including grapefruit [22], Curcuma caesia Roxb. [23], and Zingiberaceae [24], have been reported. Furthermore, essential oils not only show functional activity, but also have the advantage of reducing various side effects reported by using synthetic compounds [25]. These essential oils have been obtained from aromatic plants in various ways, such as water steam distillation, clevenger hydrodistillation, cold press extraction, and solvent extraction [26]. However, these traditional methods have several disadvantages, like low yields, toxicity of residue solvents, long extraction time, and denaturation or loss of volatile compounds due to heat treatment [27]. Nowadays, the supercritical fluid extraction (SFE) method using carbon dioxide $\left(\mathrm{CO}_{2}\right)$ has begun to be widely used for essential oils extraction and isolation from plants. Compared with traditional extraction methods, SFE has the advantage of increasing extraction efficiency, shortening the extraction time, eliminating the use of harmful organic solvents, and performing extraction at an appropriate temperature so that there is no change in the volatile compounds due to heat treatment [28].

In this study, essential oil of omija (OMEO) was prepared using a SFE method, and its chemical compositions were analyzed using gas chromatography-mass spectrometry (GC-MS). The antioxidant and anti-inflammatory activities of OMEO were determined using HaCaT cells and RAW 264.7 cells.

\section{Materials and Methods}

\subsection{Materials and Reagents}

Dulbecco's Modified Eagle's Medium (DMEM), fetal bovine serum (FBS), penicillinstreptomycin, and phosphate-buffered saline (PBS) for cell culture were purchased from Gibco-BRL (Grand Island, NY, USA). Lipopolysaccharide (LPS), thiazolyl blue tetrazolium bromide (MTT), Griess reagent, sodium nitrite solution, the 19 selected volatile compound standards ( $\alpha$-pinene, camphene, $\beta$-pinene, sabinene, 3 -carene, $\beta$-myrcene, $\alpha$-phellandrene, $\alpha$-terpinene, limonene, p-cymene, terpinolene, 2-nonanone, acetic acid, citronellal, bornyl 
acetate, thujopsene, $\beta$-chamigrene, (-)- $\beta$-bisabolene, and nerolidol) were purchased from Sigma-Aldrich Co. (St. Louis, MO, USA). In addition, $2^{\prime}, 7^{\prime}$-dichlorodihydrofluorescein diacetate $\left(\mathrm{H}_{2}\right.$ DCFDA) was obtained from Thermo Fisher Scientific (Carlsbad, CA, USA). Antibodies against iNOS, p65, phospho-p65 (p-p65), and $\beta$-actin were obtained from Santa-Cruz Biotechnology (Dallas, TX, USA). Materials for western blot were obtained from Bio-Rad (Hercules, CA, USA), and all other reagents and chemicals used were of analytical grade.

\subsection{Sample Preparation (Supercritical Fluid Extraction)}

Omija fruits were obtained from Hyojongwon Co., a local producer located in Munkyung, Korea. Omija samples were freeze dried and grinded with dry ice using a food-processor grinder (SMX-3500GN, Shinil, Seoul, Korea). The SFE using $\mathrm{CO}_{2}$ was performed using a laboratory-scale Supercritical Fluid System (Ilshin Autoclave Co., Daejeon, Korea) to produce OMEO. The extraction conditions were carried out with slight modifications according to Guan et al. [29]. The temperature was $60^{\circ} \mathrm{C}$, the pressure was $350 \mathrm{bar}$, the extraction time was $2 \mathrm{~h}$, and the $\mathrm{CO}_{2}$ flow rate was $40 \mathrm{~mL} / \mathrm{min}$. Obtained OMEO were stored at $-80^{\circ} \mathrm{C}$ in a deep freezer until further analysis. Extract yield of essential of from omija was $6.5 \%$. Extraction yield $(\% w / w)$ was calculated using the following equation:

$$
\text { Extract yield } \%=\frac{\text { Extract mass }(\mathrm{g})}{\text { Sample mass }(\mathrm{g})} \times 100
$$

\subsection{GC-MS Analysis}

The chemical compositions of OMEO were analyzed using an HP 7890 gas chromatograph coupled with an HP 5975 mass selective detector (Agilent Technologies, Palo Alto, CA, USA). All samples were analyzed with a $60 \mathrm{~m}$ DB-WAX column $(0.25 \mathrm{~mm}$ i.d., $0.25 \mu \mathrm{m}$ thickness, Agilent Technologies). Helium at a constant flow of $1 \mathrm{~mL} / \mathrm{min}$ was used as the carrier gas. The GC oven temperature programs were as follows: held at $50{ }^{\circ} \mathrm{C}$ for $1 \mathrm{~min}$ and then increased $3{ }^{\circ} \mathrm{C} / \mathrm{min}$ to $220^{\circ} \mathrm{C}$. The transfer line, ion source, and quadrupole temperature were maintained at 250,230 , and $150{ }^{\circ} \mathrm{C}$, respectively. The mass spectrum were employed in full scan mode, and the mass range was collected between $m / z 35$ and 400. The identification of the chemical compounds of OMEO was carried out using the relative peak area and retention index (Kovat's index) on DB-WAX. The quantification of chemical compounds contained in $1 \mathrm{~g}$ of the sample were relatively quantified using phenethyl alcohol added as an internal standard (ISTD) and the peak area of the identified chemical compounds (ISTD concentration $\times$ peak area of each compound/peak area of ISTD) [30].

\subsection{Cell Culture and Cell Viability}

HaCaT human keratinocyte and RAW 264.7 murine macrophages were purchased from the American Type Culture Collection (Rockville, MD, USA) and were cultured in DMEM supplemented with $10 \% \mathrm{FBS}, 1 \%$ penicillin/streptomycin at $37^{\circ} \mathrm{C}$ in a humidified incubator containing $5 \% \mathrm{CO}_{2}$.

The effect of OMEO on cell viability was determined using the MTT assay as described by Lee et al. [5]. HaCaT cells and RAW 264.7 cells were transferred to a 96-well plate at a density of $8 \times 10^{3}$ cells/well and $3 \times 10^{4}$ cells/well, respectively. Additionally, each well plate incubated at $37^{\circ} \mathrm{C}$ in a $5 \% \mathrm{CO}_{2}$ incubator for $24 \mathrm{~h}$. After that, OMEO was treated into each well at various concentrations $(6.25-100 \mu \mathrm{g} / \mathrm{mL})$ and incubated for an additional $24 \mathrm{~h}$. MTT (5 mg/mL in PBS) solution was added to each well for an additional $4 \mathrm{~h}$. The supernatant was then removed from each well, and dimethyl sulfoxide was added to each well to dissolve the MTT formazan. The absorbance of each well was measured using a microplate reader (SpectraMax M2e, Molecular Devices, San Jose, CA, USA) at $570 \mathrm{~nm}$. 
The control used cell medium instead of OMEO. Cell viability was calculated using the following equation:

$$
\text { Cell viability }(\%)=(\text { absorbance of sample } / \text { absorbance of control }) \times 100
$$

\subsection{Determination of Intracellular ROS Production}

The inhibitory effect of intracellular ROS production of OMEO was measured using $\mathrm{H}_{2}$ DCFDA fluorescent probe [31]. HaCaT cells $\left(1 \times 10^{4}\right.$ cells $/$ well $)$ were seeded into a 96-well black plate and incubated for $24 \mathrm{~h}$. After then, OMEO at various concentration $(6.25-50 \mu \mathrm{g} / \mathrm{mL})$ were treated for $1 \mathrm{~h}$ in the presence of $\mathrm{H}_{2}$ DCFDA $(2 \mu \mathrm{M})$. Subsequently, the wells were rinsed three times with PBS and irradiated with $40 \mathrm{~mJ} / \mathrm{cm}^{2}$ UV-B to generate ROS. The DCF fluorescent were measured using a Fluorescence reader (Molecular Devices) equipped with $485 / 535 \mathrm{~nm}$ excitation/emission filter.

\subsection{Determination of NO Production}

The inhibitory effect of OMEO on NO levels induced by LPS stimulation in RAW 264.7 cells was determined using Griess assay [8]. RAW 264.7 cells $\left(3 \times 10^{4}\right.$ cells/well $)$ were seeded into a 96-well plate and cultured for $24 \mathrm{~h}$. After then, OMEO at various concentration $(12.5-100 \mu \mathrm{g} / \mathrm{mL})$ were treated with LPS $(1 \mu \mathrm{g} / \mathrm{mL})$ for additional $24 \mathrm{~h}$. One hundred $\mu \mathrm{L}$ of supernatant of the medium were added to a new 96-well plate and mixed with $100 \mu \mathrm{L}$ of the Griess reagent (Sigma-Aldrich). After $15 \mathrm{~min}$ incubation at room temperature, absorbance was measured using a microplate reader at $540 \mathrm{~nm}$, and NO concentration was calculated using sodium nitrite standard solution (Sigma-Aldrich).

\subsection{Western Blot}

For western blot analysis [32], RAW 264.7 cells $\left(5 \times 10^{5}\right.$ cells/well) were seeded into a 6-well plate and cultured for $24 \mathrm{~h}$. After then, various concentration $(12.5-100 \mu \mathrm{g} / \mathrm{mL})$ of OMEO were treated with LPS $(1 \mu \mathrm{g} / \mathrm{mL})$ in each well for additional $24 \mathrm{~h}$. Total protein was extracted using RIPA buffer supplemented with protease and phosphatase inhibitor (Thermo Fisher Scientific). The concentration of protein was determined using BCA method. The same concentration $(30 \mu \mathrm{g})$ of protein was separated on a $8 \%$ SDS-PAGE gel and subsequently transferred to polyvinylidene difluoride membranes (Bio-Rad). The membrane was blocked with 5\% skim milk for $1 \mathrm{~h}$ and then incubated with primary antibody (iNOS, p65, p-p65, and $\beta$-actin) overnight at $4{ }^{\circ} \mathrm{C}$. After washing using TBST (Tris-buffered saline with $1 \%$ Tween-20) for $45 \mathrm{~min}$ ( 3 times $\times 15 \mathrm{~min}$ ), the membrane was incubated with HRP-conjugated secondary antibodies at room temperature for $2 \mathrm{~h}$. After washing using TBST for $45 \mathrm{~min}$, proteins were detected using chemiluminescence reagent (Amersham Pharmacia Biotech, Piscataway, NJ, USA) and observed with G:BOX Chemi XX6 (Syngene Ltd., Frederick, MD, USA).

\subsection{Statistical Analysis}

Results are presented as the mean \pm standard deviation from triplicate measurements of the analyses. The Student's t-test was applied to measure the significance of the difference in mean values between two groups. One-way analysis of variance (ANOVA) followed by Duncan's post hoc test $(p<0.05)$ was used to measure the significance of the difference in mean values among the multiple groups. All statistical analysis were performed using the SPSS statistics 20 (SPSS Inc., Chicago, IL, USA).

\section{Results and Discussion}

\subsection{Analysis of Chemical Composition of OMEO}

The OMEO obtained by SFE method was analyzed by GC-MS. A total of 41 compounds were identified from OMEO (Table 1 and Supplementary Figure S1), which included sesquiterpenoids (16), monoterpenoids (14), ketones (4), alcohols (3), aldehydes (2), acids (1), and aromatic hydrocarbons (1). The major compounds of OMEO were $\alpha$-ylangene 
(3505.49 $\mu \mathrm{g} / \mathrm{g}), \beta$-himachalene (1163.02 $\mu \mathrm{g} / \mathrm{g}),(-)-\beta$-elemene (801.15 $\mu \mathrm{g} / \mathrm{g}), \gamma$-terpinene $(473.63 \mu \mathrm{g} / \mathrm{g})$, and $\beta$-chamigrene $(472.84 \mu \mathrm{g} / \mathrm{g})$. These are included in the major groups sesquiterpenoids $(75.35 \%)$ and monoterpenoids $(20.32 \%)$, which account for the largest portion of total OMEO compounds.

Table 1. Chemical composition of omija (Schisandra chinensis (Turcz.) Baill.) essential oil.

\begin{tabular}{|c|c|c|c|c|c|}
\hline Peak No. & $\begin{array}{l}\mathrm{RT}^{1} \\
(\mathrm{~min})\end{array}$ & Compound Name & $\mathrm{RI}^{2}$ & $\begin{array}{c}\text { Concentration } \\
(\mu \mathrm{g} / \mathrm{g})\end{array}$ & Ratio (\%) \\
\hline 1 & 11.3 & $\alpha$-Pinene & 1020 & 213.19 & 2.42 \\
\hline 2 & 12.7 & Camphene & 1065 & 150.54 & 1.71 \\
\hline 3 & 13.07 & 2-Hexanone & 1106 & 92.04 & 1.04 \\
\hline 4 & 14.17 & $\beta$-pinene & 1108 & 72.3 & 0.82 \\
\hline 5 & 14.6 & Sabinene & 1119 & 118.69 & 1.35 \\
\hline 6 & 15.67 & 3-Carene & 1146 & 18.05 & 0.20 \\
\hline 7 & 16.05 & $\beta$-Myrcene & 1167 & 154.8 & 1.76 \\
\hline 8 & 16.3 & $\alpha$-Phellandrene & 1167 & 32.36 & 0.37 \\
\hline 9 & 16.88 & $\alpha$-Terpinene & 1176 & 68.01 & 0.77 \\
\hline 10 & 17.31 & 3-Hexanol & 1199 & 31.56 & 0.36 \\
\hline 11 & 17.66 & Limonene & 1200 & 88.07 & 1.00 \\
\hline 12 & 18.1 & $\beta$-Phellandrene & 1212 & 12.01 & 0.14 \\
\hline 13 & 18.31 & 2-Hexanol & 1210 & 53.6 & 0.61 \\
\hline 14 & 19.61 & $\gamma$-Terpinene & 1243 & 473.63 & 5.37 \\
\hline 15 & 20.66 & p-Cymene & 1266 & 94.16 & 1.07 \\
\hline 16 & 21.22 & Terpinolene & 1280 & 39.11 & 0.44 \\
\hline 17 & 22.99 & (E)-2-Heptenal & 1325 & 6.82 & 0.08 \\
\hline 18 & 25.65 & 2-Nonanone & 1386 & 5.56 & 0.06 \\
\hline 19 & 27.72 & $\begin{array}{l}\text { 1-Isopropenyl-4-methyl } \\
\text { benzene }\end{array}$ & 1421 & 2.26 & 0.03 \\
\hline 20 & 28.27 & Acetic acid & 1461 & 7.77 & 0.09 \\
\hline 21 & 28.67 & $\alpha$-Cubebene & 1463 & 4.32 & 0.05 \\
\hline 22 & 29.45 & Citronellal & 1474 & 4.79 & 0.05 \\
\hline 23 & 29.98 & $\alpha$-Ylangene & 1492 & 3505.49 & 39.75 \\
\hline 24 & 30.23 & $\alpha$-Copaene & 1488 & 52.88 & 0.60 \\
\hline 25 & 31.33 & $\beta$-Bourbonene & 1518 & 10.85 & 0.12 \\
\hline 26 & 32.01 & $\beta$-Cubebene & 1544 & 19.41 & 0.22 \\
\hline 27 & 33.34 & $\alpha$-Santalene & 1583 & 20.2 & 0.23 \\
\hline 28 & 33.8 & Bornyl acetate & 1578 & 255.95 & 2.90 \\
\hline 29 & 34.07 & $(-)-\beta$-Elemene & 1586 & 801.15 & 9.08 \\
\hline 30 & 34.54 & $\beta$-Caryophyllene & 1596 & 42.76 & 0.48 \\
\hline 31 & 35.56 & Thujopsene & 1632 & 24.29 & 0.28 \\
\hline 32 & 36.38 & $\alpha$-Himachalene & 1656 & 27.42 & 0.31 \\
\hline 33 & 37.83 & $\gamma$-Curcumene & 1695 & 27.79 & 0.32 \\
\hline 34 & 38.73 & $\beta$-Chamigrene & 1724 & 472.84 & 5.36 \\
\hline 35 & 39.17 & $(-)-\beta$-Bisabolene & 1721 & 282.6 & 3.20 \\
\hline 36 & 39.9 & $\beta$-Himachalene & 1717 & 1163.02 & 13.19 \\
\hline 37 & 40.77 & $\beta$-Sesquiphellandrene & 1771 & 73.62 & 0.83 \\
\hline 38 & 42.06 & 2-Tridecanone & 1816 & 97.77 & 1.11 \\
\hline 39 & 42.96 & Cuparene & 1816 & 117.02 & 1.33 \\
\hline 40 & 49.19 & 2-Pentadecanone & 2017 & 15.31 & 0.17 \\
\hline 41 & 49.68 & Nerolidol & 2025 & 64.38 & 0.73 \\
\hline
\end{tabular}

${ }^{1}$ RT, retention time ${ }^{2}$ RI, retention index on DB-WAX.

In our previous study, chemical compounds of omija were analyzed using a headspace stir-bar sorptive extraction-GC-MS [12]. Compared with previous studies, most terpenoid compounds were detected identically, but $\alpha$-cubebene, $\alpha$-santalene, thujopsene, $\alpha$-himachalene, $\beta$-chamigrene, and cuparene were newly detected in OMEO obtained by SFE method in the sesquiterpenoids group (Table 1). In addition, bornyl acetate in the monoterpenoids group; 2-hexanone and 2-pentadecanone in the ketones group; (E)-2heptenal and citronellal in the aldehyde group; and 3-hexanol, 2-hexanol, and nerolidol in 
the alcohols group were newly detected in OMEO obtained by SFE method (Table 1). The results of this study have also been reported in another previous study using rosemary [33]. In this study, the authors reported that when essential oil was prepared through SFE method, there was a change in chemical composition compared to essential oil prepared through the traditional hydrodistillation methods.

To our best knowledge, this is the first time that the chemical composition of the essential oil extracted from the omija produced by the SFE method via GC-MS has been reported. Some researchers reported the chemical composition of essential oil of omija; however, they analyzed the essential oil obtained through different extraction methods, such as solvent-free microwave extraction [34] and hydrodistillation [35]. Compared with our results, it was confirmed that $\alpha$-ylangene is the major compound showing the highest content among essential oil compounds. However, in our study, it was found that the proportion of monoterpenoids accounted for $20 \%$, but the content of monoterpenoids in essential oils prepared by other methods was as low as $5 \%$ or less [34,35]. As a result, it was confirmed that the chemical composition of the essential oil varies depending on the manufacturing method, which is thought to affect the bio-functionality of the OMEO.

\subsection{Antioxidant Activity of OMEO in UV-B Irradiation-Induced HaCaT Keratinocyte}

HaCaT keratinocyte cells and UV-B irradiation are experimental methods that have been commonly used to determine antioxidant activity. Since UV-B irradiation can induce changes in ROS levels in cells, it is used as a method to measure the ROS scavenging activity of different substances $[8,36]$.

Prior to confirming the effects of OMEO on the intracellular ROS levels, the effect on $\mathrm{HaCaT}$ cell viability was confirmed by MTT assay. OMEO was not cytotoxic to HaCaT cells below $50 \mu \mathrm{g} / \mathrm{mL}$. However, from the $100 \mu \mathrm{g} / \mathrm{mL}$ concentration, the cell viability decreased significantly $(p<0.05$, data not shown). Therefore, the following studies were performed at a concentration of $50 \mu \mathrm{g} / \mathrm{mL}$ or less. The effects of OMEO on intracellular ROS levels are shown in Figure 1. The sample irradiated with UV-B showed increased intracellular ROS, which means that UV-B irradiation acts as trigger to oxidative stress. Compared to the control (non UV-B treated sample), the ROS level of the UV-B irradiated sample significantly increased by about 2.19 fold $(p<0.05)$, and the ROS level was $219.34 \pm 9.56 \%$. However, pre-incubation of cells with OMEO resulted in a dose-dependent decrease in ROS levels $(p<0.05)$. At a concentration of $50 \mu \mathrm{g} / \mathrm{mL}$ of OMEO, ROS level was decreased to $141.85 \pm 3.53 \%$, and when treated with $25,12.5$, and $6.25 \mu \mathrm{g} / \mathrm{mL}$, the ROS level was decreased to $148.96 \pm 2.77 \%, 153.32 \pm 2.92 \%$, and $160.58 \pm 4.81 \%$, respectively.

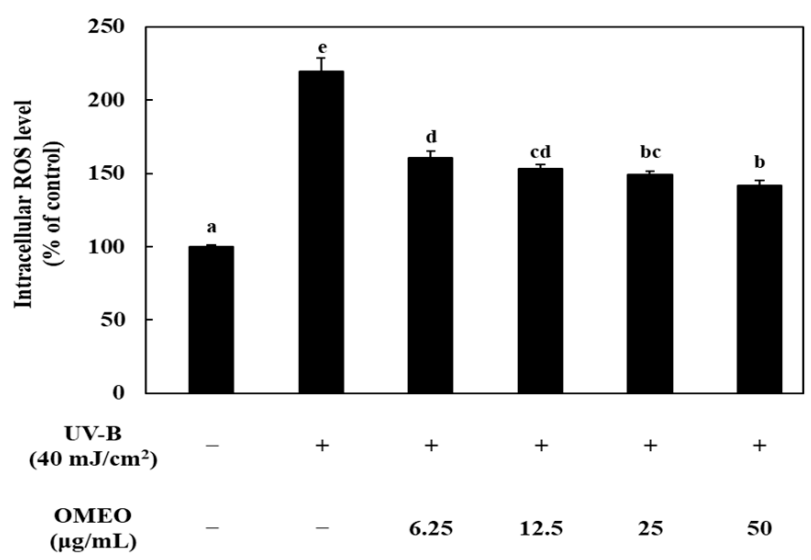

Figure 1. Effect of omija (Schisandra chinensis (Turcz.) Baill.) essential oil on the production of ROS in UV-B irradiation-induced HaCaT keratinocytes. Values are expressed as the mean \pm standard deviation. Different letters (a-e) among samples indicate significant differences by one-way ANOVA followed by Duncan's post hoc test $(p<0.05)$. control: group without UV-B irradiation. 
In order to determine which compound of the OMEO analyzed above is the key compound of OMEO antioxidant activity, the effect of each compound on the ROS level was confirmed. As a result of compound analysis of OMEO, several compounds, including major compounds $\alpha$-ylangene, $\beta$-himachalene, $(-)-\beta$-elemene, and $\gamma$-terpinene are substances that have already been widely studied for their antioxidant activity $[35,37,38]$. Therefore, 19 compounds were selected, and the effect on the ROS level was confirmed through the same experiment (19 compounds were purchased from Sigma-Aldrich Co.). The effect of each compound on the ROS level is shown in Figure 2. HaCaT cells were pre-incubated with $50 \mu \mathrm{g} / \mathrm{mL}$ of each compound to determine their effect on ROS levels and compared to the OMEO $(50 \mu \mathrm{g} / \mathrm{mL})$-treated group. Compared to the UV-B treatment group $(100 \%)$, the OMEO treatment significantly decreased ROS levels by $71.76 \pm 2.22 \%$ $(p<0.001)$. Based on the results for each compound, it was confirmed that five compounds ( $\alpha$-pinene, camphene, $\beta$-myrcene, 2-nonanone, and nerolidol) significantly decreased the ROS level by $88.03 \pm 4.22,71.93 \pm 2.28,86.27 \pm 2.31,86.11 \pm 2.18$, and $68.55 \pm 3.06 \%$, respectively ( $\alpha$-pinene, $\beta$-myrcene, 2-nonanone, $p<0.01$; camphene, nerolidol, $p<0.001$ ). On the other hand, ROS level significantly increased after pre-incubation with five compounds ( $\beta$-pinene, sabinene, 3 -carene, limonene, and p-cymene). However, the ratio of these compounds was less than $1 \%$, so it is thought that there was no significant effect on the ROS-inhibitory activity of OMEO.

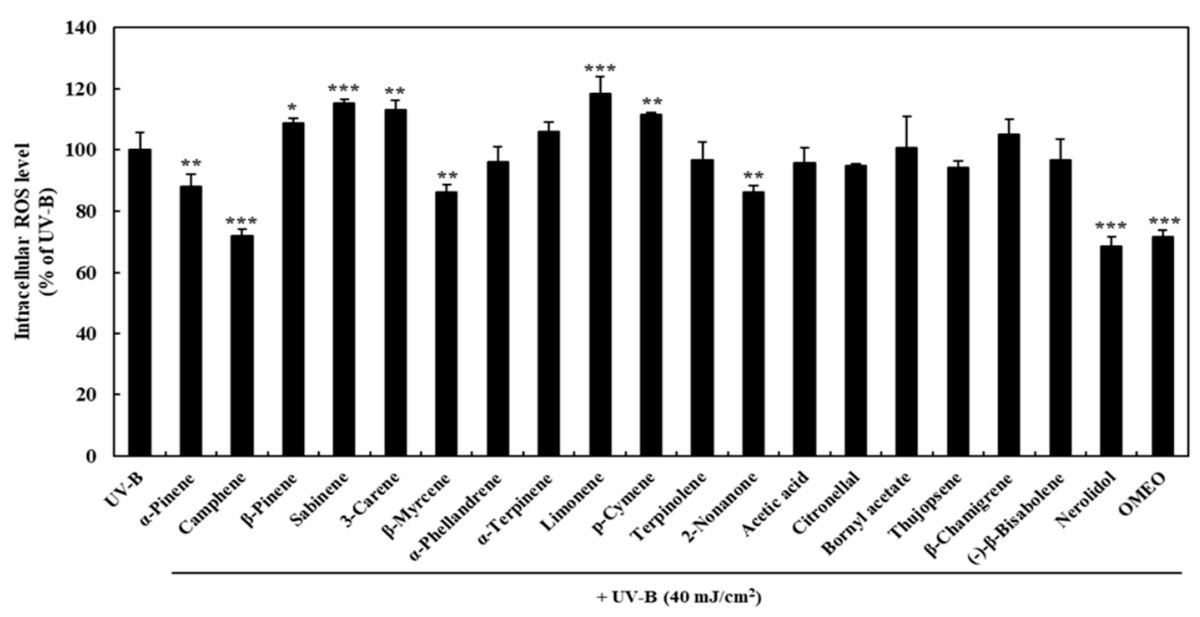

Figure 2. Effects of each compounds ( $50 \mu \mathrm{g} / \mathrm{mL}$ ) of omija (Schisandra chinensis (Turcz.) Baill.) essential oil on the production of ROS in UV-B irradiation-induced HaCaT keratinocytes. Values are expressed as the mean \pm standard deviation. ${ }^{*}, * *, * * *$ mean statistical difference for $p<0.05,0.01,0.001$ (Student's $t$-test) compared with UV-B group.

Excess intracellular ROS can damage DNA and mitochondria, causing protein oxidation, resulting in abnormal energy metabolism [39]. Moreover, excess ROS can activate the nuclear factor (NF)- $\mathrm{KB}$ pathway, and thus, it is known to cause an excessive inflammatory response as well as various diseases, such as cancer, neurologic diseases, and vascular diseases [40]. Therefore, studies on finding antioxidants capable of regulating ROS from various substances are being actively conducted $[1,8]$, and studies on the antioxidant activity of essential oils obtained from various plants have also been reported [37,41]. According to the results of this study, OMEO can reduce the production and accumulation of intracellular ROS content and inhibit the oxidative damage in UV-B-irradiated $\mathrm{HaCaT}$ cells. It is suggested that this antioxidant activity originated not only from previously reported antioxidant compounds but also from the $\alpha$-pinene, camphene, $\beta$-myrcene, 2 -nonanone, and nerolidol identified in this study.

In particular, overexpression of ROS is known to be closely related to inflammation. Jaisin et al. [36] reported that an increase in intracellular ROS plays an important role in the inflammatory response in human skin. Piperine, an alkaloid compound present 
in black and white pepper, exhibited strong ROS inhibitory activity in UV-B-irradiated cells and showed anti-inflammatory activity by inhibiting the synthesis of COX-2 and iNOS [36]. Ji et al. [8] reported that peptides from natural plant proteins effectively reduced the production of ROS in $\mathrm{H}_{2} \mathrm{O}_{2}$-induced $\mathrm{HaCa}$ T cells and also reported that it has antiinflammatory activity by inhibiting NO production through the NF- $\mathrm{B}$ pathway in RAW 264.7 cells. Therefore, it is very important to simultaneously confirm antioxidant activity and anti-inflammatory activity.

\subsection{Anti-Inflammatory Activity of OMEO in LPS-Induced RAW 264.7 Macrophages}

The effects of OMEO on NO production in RAW 264.7 cells were measured to determine whether OMEO have anti-inflammatory activity. NO is a small molecule that participates in signaling involved in a wide range of pathophysiological processes, particularly a series of processes related to inflammation [42]. When an inflammatory stimulus occurs, the production of NO increases, which mediates the pro-inflammatory effect. However, overproduction of NO can be harmful and can lead to a variety of inflammatory diseases [43]. Therefore, study of the effect on NO production is being used as a research method to confirm its ability to regulate inflammation.

Prior to confirming the NO-production inhibitory activity of OMEO, the effect of OMEO on RAW 264.7 cell viability was confirmed by MTT assay. It was confirmed that there was no cytotoxicity at all concentrations of OMEO (12.5-100 $\mu \mathrm{g} / \mathrm{mL})$, and through this, the effect on cytotoxicity was excluded from the NO-inhibition effect (data not shown). The effects of OMEO on NO production are shown in Figure 3. LPS treatment significantly increased NO production compared to the negative control $(p<0.05)$. In the negative control, the amount of NO was $5.73 \mu \mathrm{M}$; however, when LPS $(1 \mu \mathrm{g} / \mathrm{mL})$ was treated in RAW 264.7 cells, the amount of NO produced increased by 4.76 times to $27.3 \mu \mathrm{M}$. OMEO showed an inhibitory effect on NO production in a dose-dependent manner. At a concentration of $100 \mu \mathrm{g} / \mathrm{mL}$, OMEO inhibited NO production to $12.6 \mu \mathrm{M}$ by $52.17 \%$. Additionally, it was confirmed that NO production was suppressed up to 20.3, 23.1, and $24.5 \mu \mathrm{M}$ by $24.88,14.61$, and $9.69 \%$ at concentrations of 50,25 , and $12.5 \mu \mathrm{g} / \mathrm{mL}$, respectively. This level is a significant decrease compared to the LPS treatment group $(p<0.05)$. NO is synthesized by a family of nitric oxide synthases. In particular, it is known that the synthesis occurs by inducible nitric oxide synthase (iNOS) under stimulation by immunological or microbial stimuli [44]. Therefore, the effect of OMEO on iNOS protein expression was investigated using western blot analysis (Figure 4a). As a result of treating RAW 264.7 cells with LPS, it was confirmed that the expression of iNOS protein was induced compared to the control group (non-treated group). These induced iNOS protein-expression levels were significantly decreased by the treatment with OMEO $(100 \mu \mathrm{g} / \mathrm{mL}$, Figure $4 \mathrm{a})$. As a result, it was confirmed that the inhibitory activity of OMEO against NO production in RAW 264.7 cells was the result of suppressing the expression of iNOS protein.

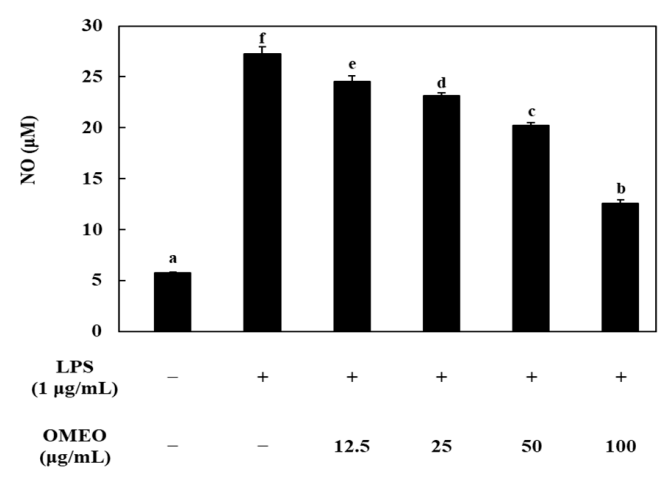

Figure 3. Effect of omija (Schisandra chinensis (Turcz.) Baill.) essential oil on the production of NO in LPS-induced RAW 264.7 macrophages. Values are expressed as the mean \pm standard deviation. Different letters (a-f) among samples indicate significant differences by one-way ANOVA followed by Duncan's post hoc test $(p<0.05)$. 
(a)

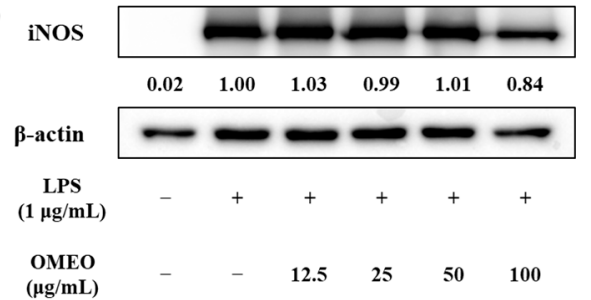

(b)

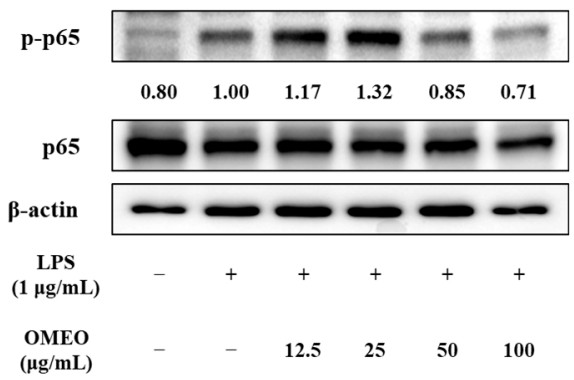

Figure 4. Effect of omija (Schisandra chinensis (Turcz.) Baill.) essential oil on the expression of iNOS protein (a) and phosphorylation of NF- $\mathrm{KB}(\mathbf{b})$ in LPS-induced RAW 264.7 macrophages. The relative amounts are expressed as iNOS/ $\beta$-actin and p-p65/p65, respectively.

The pro-inflammatory mediator is mediated by a major transcriptional regulator, such as NF- $\mathrm{kB}$. NF- $\mathrm{KB}$ positively mediates the transcription of numerous genes associated with inflammation, such as iNOS, COX-2, chemokines, and inflammatory cytokines [45]. Therefore, studies to find natural products that inhibit the NF- $\mathrm{kB}$ signaling pathway are being widely conducted for the purpose of effectively treating various inflammatory diseases [46]. In this study, the effect of OMEO on the phosphorylation of p65, a subunit of NF- $\mathrm{KB}$, was confirmed to determine whether OMEO inhibited NF- $\mathrm{KB}$ activation. As shown in Figure $4 b$, it was confirmed that the phosphorylation of p65 was increased when LPS was treated alone. However, OMEO suppressed the phosphorylation of p65 induced by LPS treatment at 50 and $100 \mu \mathrm{g} / \mathrm{mL}$ concentrations. These results suggest that OMEO inhibits NO and iNOS expression in RAW 264.7 through inhibition of NF- $\mathrm{KB}$ activation.

Other scientific researchers have reported that essential oils from various plants have anti-inflammatory activity by inhibiting the production of inflammatory mediators and suppressing the activation of cell signaling pathways $[42,46]$. These studies also reported that essential oils obtained from Citrus medica, Cirsium japonicum DC, and Campomanesia phaea showed anti-inflammatory activity by inhibiting the NF- $\mathrm{kB}$ cell signaling pathway, similar to our results. Therefore, it was confirmed that OMEO have the potential to be used as a safe and effective therapeutic agent for various inflammatory diseases.

In these various studies, research on natural, food-derived substances with antioxidant and anti-inflammatory activity is being actively conducted, and it is reported that these substances can be used as food additives added to functional foods $[8,36,42,46]$. Therefore, OMEO also has excellent antioxidant and anti-inflammatory activities, as confirmed in this study; it is expected that it can be used in various health functional foods as a food additive in the future.

\section{Conclusions}

In present study, OMEO obtained from Schisandra chinensis (Turcz.) Baill. (omija) by supercritical fluid extraction using $\mathrm{CO}_{2}$ exhibited antioxidant and anti-inflammatory activities. Through GC-MS analysis, it was confirmed that a total of 41 chemical compounds exist in OMEO. Specifically, OMEO effectively reduced the increased ROS levels in $\mathrm{HaCaT}$ keratinocyte cells by UV-B irradiation, which was confirmed to be due to some compounds ( $\alpha$-pinene, camphene, $\beta$-myrcene, 2 -nonanone, and nerolidol) present in OMEO. Additionally, OMEO significantly inhibited NO production in LPS-induced RAW 264.7 macrophages. It was confirmed that these inhibition effects of OMEO were the result of inhibiting the synthesis of iNOS by suppressing the activation of the NF- $\mathrm{kB}$ cell signaling pathway. These findings suggest that OMEO could be used as a functional food ingredient in the food industry in the future. In addition, future research should be accompanied by research on optimization of SFE methods for industrial use of OMEO. 
Supplementary Materials: The following are available online at https: / www.mdpi.com/article/ 10.3390/foods10071619/s1, Figure S1: Chromatographic profile of the S. chinensis fruit essential oil by GC-MS.

Author Contributions: Conceptualization, J.-H.L., Y.-J.J., and H.-W.J.; methodology, J.-H.L., Y.-Y.L., J.L., and H.-W.J.; software, J.-H.L., Y.-J.J., and H.-W.J.; validation, J.-H.L., Y.-Y.L., J.L., Y.-J.J., and H.-W.J.; formal analysis, J.-H.L. and Y.-J.J.; investigation, Y.-Y.L., J.L., and H.-W.J.; data curation, J.-H.L., Y.-Y.L., J.L., Y.-J.J., and H.-W.J.; writing—original draft preparation, J.-H.L., Y.-J.J., and H.-W.J.; writing-review and editing, Y.-J.J. and H.-W.J.; visualization, J.-H.L.; supervision, Y.-J.J. and H.-W.J.; All authors have read and agreed to the published version of the manuscript.

Funding: This work was supported by Korea Institute of Planning and Evaluation for Technology in Food, Agriculture, Forestry, and Fisheries (IPET) through High Value-added Food Technology Development Program, funded by Ministry of Agriculture, Food, and Rural Affairs (MAFRA; Grant \# 316050031SB010) and a research grant from Seoul Women's University (2020-0452).

Institutional Review Board Statement: Not applicable.

Informed Consent Statement: Not applicable.

Data Availability Statement: Not applicable.

Conflicts of Interest: The authors declare no conflict of interest.

\section{References}

1. Wu, J.; Huo, J.; Huang, M.; Zhao, M.; Luo, X.; Sun, B. Structural characterization of a tetrapeptide from sesame flavor-type Baijiu and its preventive effects against AAPH-induced oxidative stress in HepG2 cells. J. Agric. Food Chem. 2017, 65, 10495-10504. [CrossRef]

2. Zhao, M.; Yang, Q.; Lin, L.; Sun, B.; Wang, Y. Intracellular antioxidant activities of selected cereal phenolic extracts and mechanisms underlying the protective effects of adlay phenolic extracts on $\mathrm{H}_{2} \mathrm{O}_{2}$-induced oxidative stress in human erythrocytes. J. Funct. Food. 2017, 31, 160-171. [CrossRef]

3. Song, R.; Liang, T.; Shen, Q.; Liu, J.; Lu, Y.; Tang, C.; Chen, X.; Hou, T.; Chen, Y. The optimization of production and characterization of antioxidant peptides from protein hydrolysates of Agrocybe aegerita. LWT-Food Sci. Technol. 2020, 134, 109987. [CrossRef]

4. Wang, L.; Ding, L.; Yu, Z.; Zhang, T.; Ma, S.; Liu, J. Intracellular ROS scavenging and antioxidant enzyme regulating capacities of corn gluten meal-derived antioxidant peptides in HepG2 cells. Food Res. Int. 2016, 90, 33-41. [CrossRef]

5. Lee, J.H.; Moon, S.H.; Kim, H.S.; Park, E.; Ahn, D.U.; Paik, H.D. Immune-enhancing activity of phosvitin by stimulating the production of pro-inflammatory mediator. Poult. Sci. 2017, 96, 3872-3878. [CrossRef] [PubMed]

6. Redza-Dutordoir, M.; Averill-Bates, D.A. Interactions between reactive oxygen species and autophagy special issue: Death mechanisms in cellular homeostasis. Biochim. Biophys. Acta-Mol. Cell Res. 2021, 1868, 119041. [CrossRef] [PubMed]

7. Kwon, N.; Kim, D.; Swamy, K.M.K.; Yoon, J. Metal-coordinated fluorescent and luminescent probes for reactive oxygen species (ROS) and reactive nitrogen species (RNS). Coord. Chem. Rev. 2021, 427, 213581. [CrossRef]

8. Ji, Z.; Mao, J.; Chen, S.; Mao, J. Antioxidant and anti-inflammatory activity of peptides from foxtail millet (Setaria italica) prolamins in HaCaT cells and RAW264.7 murine macrophages. Food Biosci. 2020, 36, 100636. [CrossRef]

9. Liu, M.; Zhang, G.; Naqvi, S.; Zhang, F.; Kang, T.; Duan, Q.; Wang, Z.; Xiao, S.; Zheng, Y. Cytotoxicity of Saikosaponin A targets HEKa cell through apoptosis induction by ROS accumulation and inflammation suppression via NF- $\mathrm{kB}$ pathway. Int. Immunopharmacol. 2020, 86, 106751. [CrossRef]

10. Wang, Y.; Song, Y.; Zhong, Q.; Wu, Y.; Zhuang, J.; Qu, F.; Xu, C. Suppressing ROS generation by apocynin inhibited cyclic stretch-induced inflammatory reaction in HPDLCs via a caspase-1 dependent pathway. Int. Immunopharmacol. 2020, 90, 107129. [CrossRef]

11. Park, M.; Lee, K.G. Effect of roasting temperature and time on volatile compounds, total polyphenols, total flavonoids, and lignan of omija (Schisandra chinensis Baillon) fruit extract. Food Chem. 2021, 338, 127836. [CrossRef]

12. Kim, M.K.; Lee, Y.Y.; Lee, K.G.; Jang, H.W. Instrumental volatile flavor analysis of omija (Schisandra chinesis Baillon) using headspace stir-bar sorptive extraction-gas chromatography-mass spectrometry and its relationship to human sensory perceptions. Food Res. Int. 2019, 120, 650-655. [CrossRef]

13. Panossian, A.; Wikman, G. Pharmacology of Schisandra chinensis Bail: An overview of Russian research and uses in medicine. J. Ethnopharmacol. 2008, 118, 183-212. [CrossRef]

14. Huang, S.X.; Han, Q.B.; Lei, C.; Pu, J.X.; Xiao, W.L.; Yu, J.L.; Yang, L.M.; Xu, H.X.; Zheng, Y.T.; Sun, H.D. Isolation and characterization of miscellaneous terpenoids of Schisandra chinensis. Tetrahedron 2008, 64, 4260-4267. [CrossRef]

15. Li, Z.; He, X.; Liu, F.; Wang, J.; Feng, J. A review of polysaccharides from Schisandra chinensis and Schisandra sphenanthera: Properties, functions and applications. Carbohydr. Polym. 2018, 184, 178-190. [CrossRef]

16. Stacchiotti, A.; Volti, G.L.; Lavazza, A.; Rezzani, R.; Rodella, L.F. Schisandrin B stimulates a cytoprotective response in rat liver exposed to mercuric chloride. Food Chem. Toxicol. 2009, 47, 2834-2840. [CrossRef] 
17. Choi, Y.H. Schisandrin A prevents oxidative stress-induced DNA damage and apoptosis by attenuating ROS generation in C2C12 cells. Biomed. Pharmacother. 2018, 106, 902-909. [CrossRef] [PubMed]

18. Guo, M.; An, F.; Yu, H.; Wei, X.; Hong, M.; Lu, Y. Comparative effects of schisandrin A, B, and C on Propionibacterium acnes-induced, NLRP3 inflammasome activation-mediated IL-1 $\beta$ secretion and pyroptosis. Biomed. Pharmacother. 2017, 96, 129-136. [CrossRef]

19. Hwang, E.T.; Joo, Y.E.; Kim, K.R.; Jeong, J. Biomineralized separation, concentration, and evaluation of the effectiveness of Schisandra chinensis fruit extract. Food Chem. 2021, 360, 130063. [CrossRef] [PubMed]

20. Chen, X.; Tang, R.; Liu, T.; Dai, W.; Liu, Q.; Gong, G.; Song, S.; Hu, M.; Huang, L.; Wang, Z. Physicochemical properties, antioxidant activity and immunological effects in vitro of polysaccharides from Schisandra sphenanthera and Schisandra chinensis. Int. J. Biol. Macromol. 2019, 131, 744-751. [CrossRef] [PubMed]

21. Khalil, N.; Ashour, M.; Fikry, S.; Singab, A.N.; Salama, O. Chemical composition and antimicrobial activity of the essential oils of selected Apiaceous fruits. Future J. Pharm. Sci. 2018, 4, 88-92. [CrossRef]

22. Özogul, Y.; Özogul, F.; Kulawik, P. The antimicrobial effect of grapefruit peel essential oil and its nanoemulsion on fish spoilage bacteria and food-borne pathogens. LWT-Food Sci. Technol. 2021, 136, 110362. [CrossRef]

23. Borah, A.; Paw, M.; Gogoi, R.; Loying, R.; Sarma, N.; Munda, S.; Pandey, S.K.; Lal, M. Chemical composition, antioxidant, anti-inflammatory, anti-microbial and in-vitro cytotoxic efficacy of essential oil of Curcuma caesia Roxb. leaves: An endangered medicinal plant of North East India. Ind. Crop. Prod. 2019, 129, 448-454. [CrossRef]

24. Zhang, L.; Liang, X.; Ou, Z.; Ye, M.; Shi, Y.; Chen, Y.; Zhao, J.; Zheng, D.; Xiang, H. Screening of chemical composition, antiarthritis, antitumor and antioxidant capacities of essential oils from four Zingiberaceae herbs. Ind. Crop. Prod. 2020, $149,112342$. [CrossRef]

25. Ghazanfari, N.; Mortazavi, S.A.; Yazdi, F.T.; Mohammadi, M. Microwave-assisted hydrodistillation extraction of essential oil from coriander seeds and evaluation of their composition, antioxidant and antimicrobial activity. Heliyon 2020, 6, e04893. [CrossRef] [PubMed]

26. González-Mas, M.C.; Rambla, J.L.; López-Gresa, M.P.; Blázquez, M.A.; Granell, A. Volatile compounds in Citrus essential oils: A comprehensive review. Front. Plant Sci. 2019, 10, 12. [CrossRef]

27. Ebrahimzadeh, H.; Yamini, Y.; Sefidkon, F.; Chaloosi, M.; Pourmortazavi, S.M. Chemical composition of the essential oil and supercritical $\mathrm{CO}_{2}$ extracts of Zataria multiflora Boiss. Food Chem. 2003, 83, 357-361. [CrossRef]

28. Yousefi, M.; Rahimi-Nasrabadi, M.; Pourmortazavi, S.M.; Wysokowski, M.; Jesionowski, T.; Ehrlich, H.; Mirsadeghi, S. Supercritical fluid extraction of essential oils. Trac-Trends Anal. Chem. 2019, 118, 182-193. [CrossRef]

29. Guan, W.; Li, S.; Yan, R.; Tang, S.; Quan, C. Comparison of essential oils of clove buds extracted with supercritical carbon dioxide and other three traditional extraction methods. Food Chem. 2007, 101, 1558-1564. [CrossRef]

30. Cha, J.; Chin, Y.W.; Lee, J.Y.; Kim, T.W.; Jang, H.W. Analysis of volatile compounds in soju, a Korean distilled spirit, by SPME-Arrow-GC/MS. Foods 2020, 9, 1422. [CrossRef]

31. Xiao, Z.; Yang, S.; Chen, J.; Li, C.; Zhou, C.; Hong, P.; Sun, S.; Qian, Z.J. Trehalose against UVB-induced skin photoaging by suppressing MMP expression and enhancing procollagen I synthesis in HaCaT cells. J. Funct. Food. 2020, 74, 104198. [CrossRef]

32. Ahn, J.; Ha, T.Y.; Ahn, J.; Jung, C.H.; Seo, H.D.; Kim, M.J.; Kim, Y.S.; Jang, Y.J. Undaria pinnatifida extract feeding increases exercise endurance and skeletal muscle mass by promoting oxidative muscle remodeling in mice. FASEB J. 2020, 34, 8068-8081. [CrossRef]

33. Conde-Hernández, L.A.; Espinosa-Victoria, J.R.; Trejo, A.; Guerrero-Beltrán, J.Á. $\mathrm{CO}_{2}$-supercritical extraction, hydrodistillation and steam distillation of essential oil of rosemary (Rosmarinus officinalis). J. Food Eng. 2017, 200, 81-86. [CrossRef]

34. Chen, X.; Zhang, Y.; Zu, Y.; Fu, Y.; Wang, W. Composition and biological activities of the essential oil from Schisandra chinensis obtained by solvent-free microwave extraction. LWT-Food Sci. Technol. 2011, 44, 2047-2052. [CrossRef]

35. Chen, X.; Zhang, Y.; Zu, Y.; Yang, L. Chemical composition and antioxidant activity of the essential oil of Schisandra chinensis fruits. Nat. Prod. Res. 2012, 26, 842-849. [CrossRef]

36. Jaisin, Y.; Ratanachamnong, P.; Wongsawatkul, O.; Watthammawut, A.; Malaniyom, K.; Natewong, S. Antioxidant and antiinflammatory effects of piperine on UV-B-irradiated human HaCaT keratinocyte cells. Life Sci. 2020, 263, 118607. [CrossRef]

37. Ranjbaran, A.; Kavoosi, G.; Mojallal-Tabatabaei, Z.; Ardestani, S.K. The antioxidant activity of Trachyspermum ammi essential oil and thymol in murine macrophages. Biocatal. Agric. Biotechnol. 2019, 20, 101220. [CrossRef]

38. Chen, J.; Duan, W.; Bai, R.; Yao, H.; Shang, J.; Xu, J. Design, synthesis and antioxidant activity evaluation of novel $\beta$-elemene derivatives. Bioorg. Med. Chem. Lett. 2014, 24, 3407-3411. [CrossRef] [PubMed]

39. Na, E.J.; Ryu, J.Y. Anti-inflammatory effects of prunin on UVB-irradiated human keratinocytes. Biomed. Dermatol. 2018, 2, 14. [CrossRef]

40. Yang, S.; Lian, G. ROS and diseasese: Role in metabolism and energy supply. Mol. Cell. Biochem. 2020, 467, 1-12. [CrossRef] [PubMed]

41. Kavoosi, G.; Rowshan, V. Chemical composition, antioxidant and antimicrobial activities of essential oil obtained from Ferula assa-foetida oleo-gum-resin: Effect of collection time. Food Chem. 2013, 138, 2180-2187. [CrossRef]

42. Kim, K.N.; Ko, Y.J.; Yang, H.M.; Ham, Y.M.; Roh, S.W.; Jeon, Y.J.; Ahn, G.; Kang, M.C.; Yoon, W.J.; Kim, D.; et al. Anti-inflammatory effect of essential oil and its constituents from fingered citron (Citrus medica L. var. sarcodactylis) through blocking JNK, ERK and NF-kB signaling pathways in LPS-activated RAW 264.7 cells. Food Chem. Toxicol. 2013, 57, 126-131. [PubMed]

43. Sharma, J.N.; Al-Omran, A.; Parvathy, S.S. Role of nitric oxide in inflammatory diseases. Inflammopharmacology 2007, 15, 252-259. [CrossRef] [PubMed] 
44. Lind, M.; Hayes, A.; Caprnda, M.; Petrovic, D.; Rodrigo, L.; Kruzliak, P.; Zulli, A. Inducible nitric oxide synthase: Good or bad? Biomed. Pharmacother. 2017, 93, 370-375. [CrossRef] [PubMed]

45. Gloire, G.; Legrand-Poels, S.; Piette, J. NF-кB activation by reactive oxygen species: Fifteen years later. Biochem. Pharmacol. 2006, 72, 1493-1505. [CrossRef] [PubMed]

46. Lorençoni, M.F.; Figueira, M.M.; e Silva, M.V.T.; Schmitt, E.F.P.; Endringer, D.C.; Scherer, R.; Barthm, T.; Bertolucci, S.K.V.; Fronza, M. Chemical composition and anti-inflammatory activity of essential oil and ethanolic extract of Campomanesia phaea (O. Berg.) Landrum leaves. J. Ethnopharmacol. 2020, 252, 112562. [CrossRef] 